\title{
Daily Dynamics of Sugar and Phenol Contents in Apple Fruitlets during June Drop
}

\author{
Jerneja JAKOPIC*, Franci STAMPAR, Robert VEBERIC \\ University of Ljubljana, Biotechnical Faculty, Department of Agronomy, Jamnikarjeva 101, SI-1000 Ljubljana, \\ Slovenia; jerneja.jakopic@bf.uni-lj.si (*correspondingauthor);franci.stampar@bf.uni-lj.si; robert.veberic@bf.uni-lj.si
}

\begin{abstract}
The occurrence of the abscission signal in young developing fruits on apple trees (Malus domestica) was studied. Apple has a natural system of fruitlet shedding, so called June drop. Although physiological fruit drop is unable to guarantee production of marketable apples and avoid alternate bearing, knowledge of this is a key background for successful fruit thinning. A study was carried out on apple trees cv. 'Golden Delicious' during June drop. On three dates (beginning, middle and end of June drop), the daily dynamics of HPLC detected individual sugar and spectrophotometrically detected total phenolic content was investigated in central (K) and lateral (L) fruitlets. The results of daily dynamics showed the highest sugar contents at 2 p.m. On the final sampling date, on $2^{\text {nd }}$ July 2015, we observed a significant difference between sugar contents at 2 p.m. and the morning and afternoon measurements. Contents of sugars in $\mathrm{K}$ and $\mathrm{L}$ fruitlets were not significantly different. Total phenolic content at the beginning of June drop was higher than at the end. There was no statistically significant difference between $\mathrm{K}$ and $\mathrm{L}$ in an individual time period, while there were statistically significant differences in total phenolic content among the sampling dates. Although sugar and phenolic content in $\mathrm{K}$ and $\mathrm{L}$ fruitlets were rarely statistically different, their contents changed during June drop. In general, sugar contents increased and phenolic content decreased during the process, while the daily dynamic depended on weather conditions.
\end{abstract}

Keywords: abscission, carbohydrates, central fruitlet, king flower, lateral fruitlets, sucrose

\section{Introduction}

Abscission of young fruitlets is a widespread phenomenon in many fruit trees. For some species, fruitlet shedding is more or less sufficient for a regular and abundant yield (some Citrus species), for others it may be too strong for high quality and yield (such as mango, avocado), while for most temperate fruit crops (e.g., apple, pear, peach, plums), the self-regulatory mechanism is entirely insufficient to guarantee the required quality standards (Bangerth, 2000). This unsatisfactory selfregulation of fruitlet shedding leads to many disadvantages. In addition to low and unacceptable market quality in the current year, it inhibits differentiation (flower bud induction) for the next growing season, which causes alternate bearing. An apple tree produces 10 to 15 times more flowers and potential fruit than desirable at harvest. Because of this, $90-95 \%$ of the fruits must fall off to avoid over-cropping (Lakso and Goffinet, 2013). To overcome these shortcomings, flower- and/or fruitlet thinning is an efficient and necessary measure in apple fruit production (Dennis, 2000; Jakopic et al., 2013; Lakso and Goffinet,
2013). More precise knowledge of the mechanism underlying this process of natural fruit abscission would help to improve current thinning practice (Bangerth, 2000; Jakopic et al., 2016; Jakopic et al., 2015).

Detailed studies of apples during natural shedding have been performed. The cultivar 'Golden Delicious' developed clusters with 3 up to 7 flowers, with clusters of 5 flowers being the most frequent (Jakopic et al., 2015). Monitoring natural shedding showed that fruitlets in the central position were frequently unaffected by this process and usually developed to fruit. A high tendency to abscission was detected for lateral fruitlets nearest to the king flower (Jakopic et al., 2015), although it was generally true that abscission increased down the peduncle. The disadvantage of these fruitlets was further confirmed at harvest, with fruits from this position being smaller and firmer in comparison to both central and one or two positions lower than L2 (Jakopic et al., 2015). In addition, fruitlets prone to abscission reduce their growth one to two weeks prior to abscission (Jakopic et al., 2015; Magein, 1989). This may be linked to lower sink strength of lateral fruits (Blanke, 2009) and/or reduced growth of fruitlets. Growing fruitlets are mainly heterotrophic, with $95 \%$ of their carbohydrates 
76

coming from the surrounding leaves (Blanke et al., 1987). This is dependent on competition for assimilates among fruitlets, as well as fruitlets and shoots (Dal Cin et al., 2006).

These results at least partly confirm the carbohydrate theory of apple fruitlet shedding. Two main theories exist to explain fruitlet abscission. In addition to the carbohydrate theory, there is also a hormonal theory. In the latter, there is a dominance hierarchy among fruitlets in a cluster. The central fruitlet develops first and therefore has the strongest auxin transport, which inhibits auxin transport of nearby lateral fruitlets, causing them to abscise (Bangerth et al., 2000). Scientists support both theories and many studies have been conducted to validate them.

Yamaki (2010) discusses the influence of sink strength during the various steps between photoassimilate synthesis in leaves and its accumulation in fruit. In addition, sugars improve fruit quality because they are the primary substrate of various fruit components. Phenolics can be synthesized as an answer to various types of stress and could be an indicator for abscission which is regulated by a highly programmed developmental process and additionally promoted by stress.

There have been some studies of diurnal changes in sugar content in leaves of Vitis vinifera (Hunter et al., 1994), citrus fruit (Nebauer et al., 2011) and apples (Klages et al., 2001) but investigations of sugars and phenolic changes in fruits are rare or even lacking (Klages et al., 2001). To the best of our best knowledge there have been no investigations of the daily dynamics of individual sugars and phenols in apple fruitlets before, during and at the end of June drop.

The aim of the study was to determine the diurnal dynamic of changes in content of non-structural carbohydrates and total phenolics of apple fruitlets from various positions in a cluster during June drop.

\section{Materials and Methods}

\section{Plantmaterial}

The study was carried out in the experimental orchard of the Biotechnical Faculty in Ljubljana on apple trees of cv. 'Golden Delicious' grafted on rootstock M9 in 2015. The training system was solaxe. Natural shedding was monitored on uniform trees. Flower clusters with 5 flowers were selected. Four sampling dates were chosen; (1) soon after bloom ( $6^{\text {th }}$ May) at $\mathrm{K}$ fruitlet diameter $7 \mathrm{~mm}$ and $\mathrm{L}$ fruitlet diameter $5 \mathrm{~mm},(2)$ at the beginning of June drop $\left(20^{\text {th }}\right.$ May) at $\mathrm{K}$ fruitlet diameter $20 \mathrm{~mm}$ and $\mathrm{L}$ fruitlet diameter $19 \mathrm{~mm}$, (3) during June drop ( $5^{\text {th }}$ June) at $\mathrm{K}$ fruitlet diameter $30 \mathrm{~mm}$ and $\mathrm{L}$ fruitlet diameter $28 \mathrm{~mm}$ and (4) end of the natural drop ( $2^{\text {nd }} \mathrm{July}$ ) at $\mathrm{K}$ fruitlet diameter $44 \mathrm{~mm}$ and $\mathrm{L}$ fruitlet diameter $42 \mathrm{~mm}$ (Table 1). On all sampling dates clusters without fruitlets with signs of proven to abscise (pedicel yellowing) were chosen. On each of the days, the diurnal dynamics of sugar and phenolic content were monitored at two-hourly intervals from 8:00 until 20:00. At each sampling time, 7 clusters were chosen from whole trees. On the first three sampling dates, 5-flower clusters and on the last sampling date 3-flower clusters with a central (king) fruitlet were chosen for analysis. Samples were transferred to the laboratory and immediately analyzed.

For chemical analysis, central (K) and lateral (L) flowers were separated and $1 \mathrm{~g}$ of plant material was used for determination of sugars and $1 \mathrm{~g}$ for phenolic compounds.

\section{Weather conditions}

The year 2015 was warmer than the average for the last 30-year period. Conditions for apple bloom were good, with dry days prevailing in April, while in May it was warm and there was rainfall in the second half of May (meteo.si, 2017).

\section{Sample preparation}

For analysis of sugars, the plant material was extracted with $20 \mathrm{~mL}$ of bidistilled water, homogenized with an Ultra-Turrax (Ika Labortechnik, Germany) and left for half-an-hour on a shaker at $150 \mathrm{rpm}$. Samples were then centrifuged at 10,000 rpm for $10 \mathrm{~min}$ (Eppendorf Centrifuge 5810, Germany). The supernatant was filtered through a $0.2 \mu \mathrm{m}$ cellulose filter into vials and stored at $-20^{\circ} \mathrm{C}$ prior to HPLC analysis.

For phenolic analysis, the plant material was extracted with $10 \mathrm{~mL}$ of methanol with $3 \%$ formic acid (v/v) in a cold ultrasonic bath for an hour at $0{ }^{\circ} \mathrm{C}$. Samples were then centrifuged at 10,000 rpm for $10 \mathrm{~min}$ (Eppendorf Centrifuge 5810, Germany). The supernatant was filtered through a $0.2 \mu \mathrm{m}$ polyamide filter and transferred into vials and stored at $-20{ }^{\circ} \mathrm{C}$ prior to analysis on a spectrophotometer.

\section{Sugars determination}

Individual sugars were determined using high performance liquid chromatography combined with an RI detector (Thermo Scientific, Finnigan Spec-tra System, Waltham, MA, USA), as previously described by Jakopic et al. (2016). The volume of injection was $20 \mu \mathrm{l}$, components were separated on a Rezex column (Phenomenex, Rezex RCM-Monosaccharide) heated to $65^{\circ} \mathrm{C}$ at a flow of mobile phase (bidistilled water) of $0.6 \mathrm{ml} \mathrm{min}{ }^{-1}$. Individual sugars were identified on the basis of retention times and comparison to external standards. The results are presented in $\mathrm{mg} \mathrm{g}^{-1}$ dry weight (DW).

\section{Phenols determination}

Total phenolic contents were detected by spectrometer, using Folin-Ciocalteu reagent as described by Singleton and

Table 1. Sampling dates, days after full bloom and some weather conditions

\begin{tabular}{|c|c|c|c|c|c|c|}
\hline Sampling & Date & DAFB & Developmental stage & $\begin{array}{c}\text { Average cloudy } \\
(\%) \\
\end{array}$ & $\begin{array}{c}\text { Duration of solar } \\
\text { radiation }(\mathrm{h})\end{array}$ & $\begin{array}{c}\text { Rainfall } \\
(\mathrm{mm})\end{array}$ \\
\hline 1 st & 6th May & 8 & End of blooming & 37 & 9.9 & 0.0 \\
\hline $2 \mathrm{nd}$ & 20th May & 22 & Beginning of June drop & 67 & 6.6 & 0.3 \\
\hline $3 r d$ & 5th June & 38 & During June drop & 20 & 13.4 & 0.0 \\
\hline 4 th & 2nd July & 64 & End of June drop & 33 & 12.6 & 0.0 \\
\hline
\end{tabular}

DAFB, days after full bloom 
Rossi (1965). To $6 \mathrm{ml}$ bidistilled water, $100 \mu \mathrm{l}$ of samples, $500 \mu \mathrm{l}$ Folin-Ciocalteu reagent and $1.5 \mathrm{ml}$ of $20 \%$ sodium carbonate were added and diluted to $10 \mathrm{ml}$ with bidistilled water. Samples were mixed and left at $40{ }^{\circ} \mathrm{C}$ for half an hour. The absorption of individual samples was then measured at $765 \mathrm{~nm}$ using a spectrophotometer (PerkinElmer, UV/visible Lambda Bio 20). Total phenolic contents were calculated using the calibration curve for gallic acid and the results are presented in $\mathrm{mg}$ gallic acid equivalents (GAE) per kg DW.

\section{Statistical analyses}

Data were statistically evaluated using the Statgraphics (4.0) program. Multifactor analysis of variance (ANOVA) was used to test the interaction between time of day and fruitlet position in a cluster. One way ANOVA was used to test differences between times of day and the position in the cluster, and multiple range tests (Duncan's for times on day; t-test for position in cluster) were performed. Differences were judged to be statistically significant at $p \leq 0.05$.

\section{Results and Discussion}

The period of June drop has high importance in apple fruit production. Attention was therefore paid in our study to the beginning of fruit development. Four sampling dates during first the two months were chosen (Table 1, Fig. 1).

During this period, the growth of young apple fruitlets is very intensive; not only the diameter and fresh weight of fruitlets as has been previously reported (Jakopic et al., 2016; Jakopic et al., 2015) but also dry matter content (Fig. 2 ), in which the increase is statistically significantly more intensive in central (king) fruitlets $(\mathrm{K})$ than in lateral fruitlets (L). Fruitlet growth in the first weeks of their development is a consequence of cell division (Lakso and Goffinet, 2013) and dry matter production continues very intensively.

The contents of individual sugars (sucrose, glucose, fructose) and a sugar alcohol (sorbitol) in apple fruitlets were analyzed throughout the day on the same sampling dates. Both factors, the time and position in the cluster, as well as their interaction, were evaluated to check their influence on sugar content. The interaction between fruitlets position in a cluster and time of a day was not statistically significant for any individual sugar, nor for the sum of sugars on any sampling date, with the exception of glucose content on the first sampling date (Table 2). Since there were no interactions, these results show that sugar daily dynamics did not differ between central and lateral fruitlets.

On the other hand, the results of ANOVA showed that both individual factors influenced the contents of both individual and total sugars (Table 2).

\section{Seasonal changes of sugar content}

On the first sampling date, before the June drop, glucose had the highest share among sugars. Its content in apple fruitlets was highest at 2 p.m. (14:00) (55.02 $\left.\mathrm{mg} \mathrm{g}^{-1} \mathrm{DW}\right)$. Other sugars also reached their highest content levels at the same time, although differences among times were not

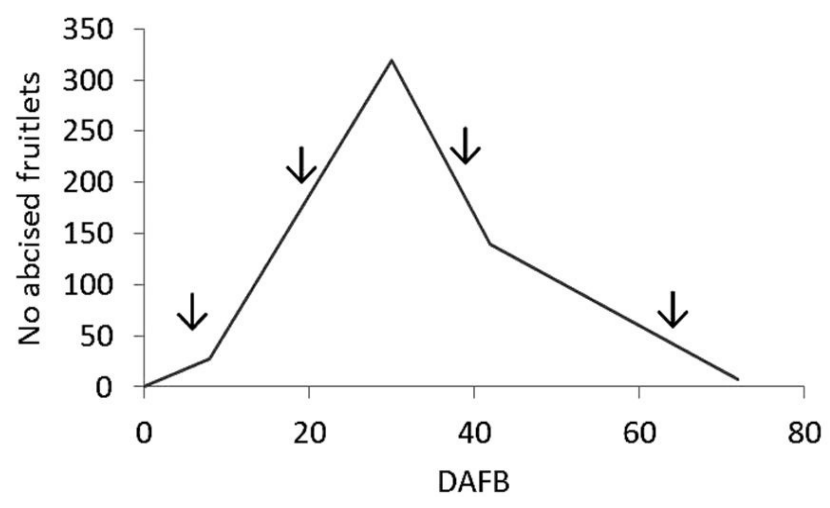

Fig. 1. Number of abscised 'Golden Delicious' apple fruitlets during the shedding process. Arrows indicate sampling dates. DAFB, days after full bloom

Table 2. Statistical analyzes for individual and sum of sugar content $\left(\mathrm{mg} \mathrm{g}^{-1} \mathrm{DW}\right)$ in fruitlets. Statistical differences for statistical multifactor ANOVA are shown

\begin{tabular}{|c|c|c|c|c|}
\hline Sampling date & Sugar & $\mathrm{K} / \mathrm{L}$ & Time & Interaction \\
\hline \multirow[t]{5}{*}{$6^{\text {th }}$ May } & Sucrose & $* * *$ & $* * *$ & n.s. \\
\hline & Glucose & $* * *$ & *** & $* * *$ \\
\hline & Fructose & *** & $* * *$ & n.s. \\
\hline & Sorbitol & *** & $* * *$ & n.s. \\
\hline & Sum of sugars & $* * *$ & $* * *$ & n.s. \\
\hline \multirow[t]{5}{*}{$20^{\text {th }}$ May } & Sucrose & n.s. & $* * *$ & n.s. \\
\hline & Glucose & $* *$ & $* * *$ & n.s. \\
\hline & Fructose & $* *$ & *** & n.s. \\
\hline & Sorbitol & n.s. & $* * *$ & n.s. \\
\hline & Sum of sugars & $* * *$ & $* * *$ & n.s. \\
\hline \multirow[t]{5}{*}{$5^{\text {th }}$ June } & Sucrose & n.s. & $* * *$ & n.s. \\
\hline & Glucose & $* * *$ & $* * *$ & n.s. \\
\hline & Fructose & $* * *$ & $* * *$ & n.s. \\
\hline & Sorbitol & n.s. & $*$ & n.s. \\
\hline & Sum of sugars & $* * *$ & $* * *$ & n.s. \\
\hline \multirow[t]{5}{*}{$2^{\text {nd }}$ July } & Sucrose & n.s. & $* * *$ & n.s. \\
\hline & Glucose & n.s. & $* * *$ & n.s. \\
\hline & Fructose & n.s. & *** & n.s. \\
\hline & Sorbitol & n.s. & $* * *$ & n.s. \\
\hline & Sum of sugars & n.s. & $* * *$ & n.s. \\
\hline
\end{tabular}


78

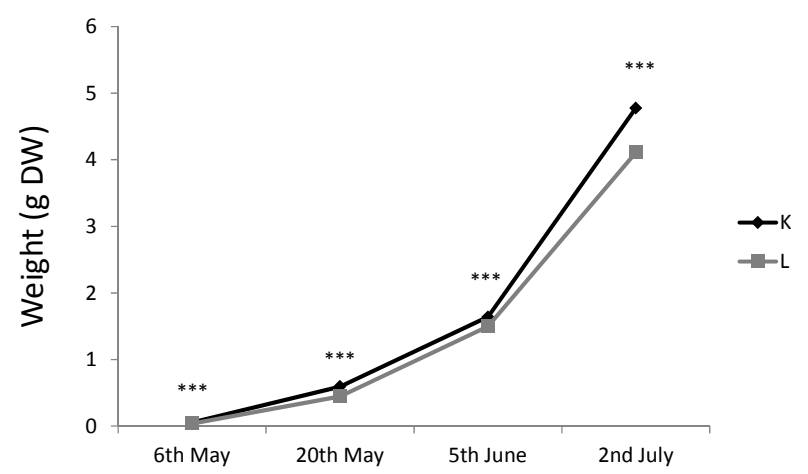

Fig. 2. Dry weight of king $(\mathrm{K})$ and lateral (L) fruitlets on individual sampling dates. Asterisks denote significant differences $(p<0.001)$

statistically significant in the case of sucrose and fructose (Table 2). Two weeks later, all sugars in apple fruitlets were in higher amounts, with the exception of sorbitol, the contents of which stayed at a similar level. On later sampling dates, the contents of glucose and fructose additionally increased, the average sucrose content slightly decreased, while sorbitol contents clearly decreased on each of the next sampling dates.

From the first until the last sampling date, the content of glucose increased more than 5 -fold and fructose almost 10fold. Fructose is mainly accumulated in fruit (Hecke et al., 2006; Sturm and Stampar, 1999). The results of seasonal changes in sugar contents are at least partly consistent with the findings of Berüter (1983) and Jakopic et al. (2016), who also reported slightly decreasing sorbitol content and increasing fructose content during natural fruitlet shedding in June.

Total sugar content in apple fruitlets increased during June drop, mainly because of an intensive increase of both fructose and glucose.
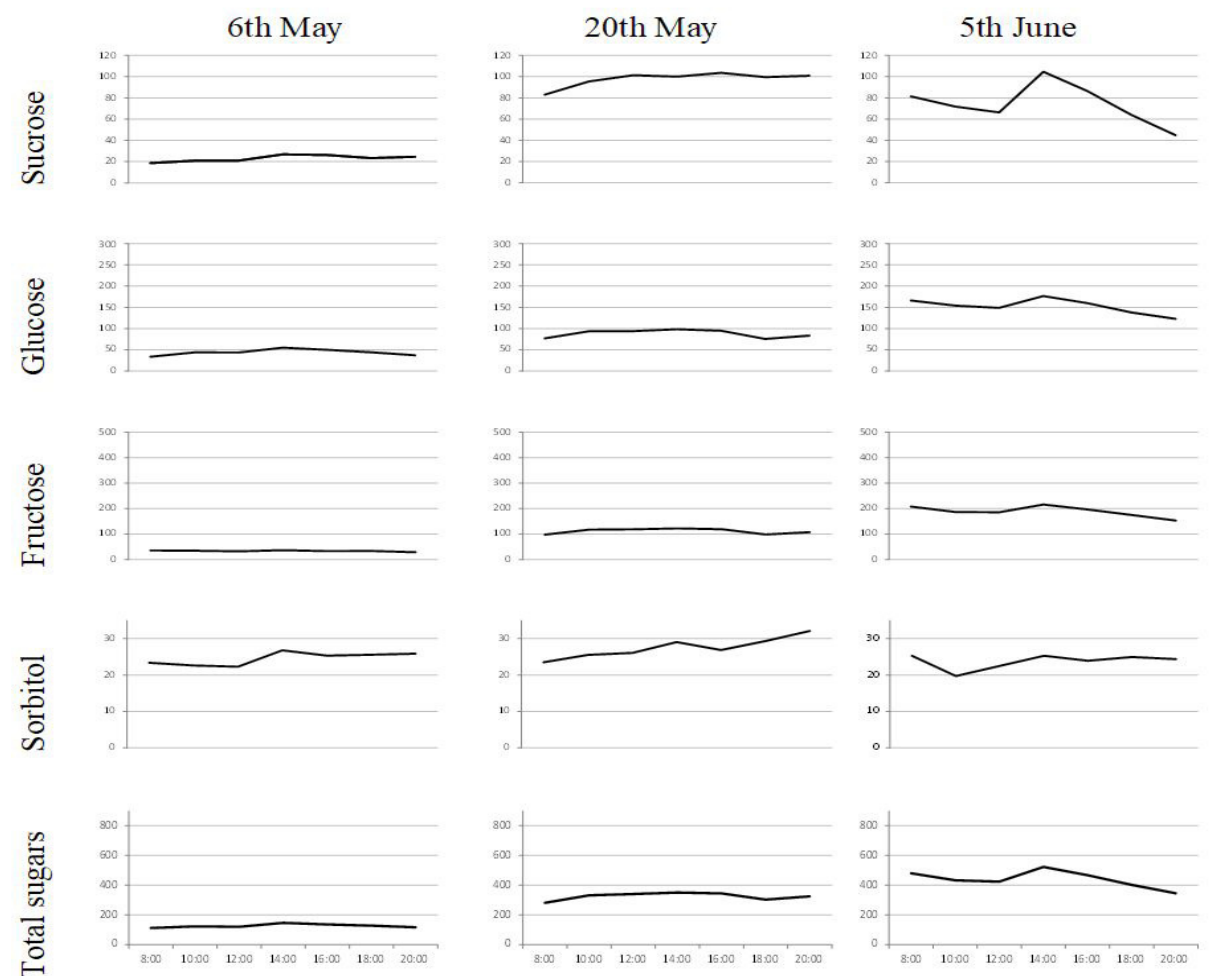

\section{Daily dynamic of sugars content}

The daily dynamic of individual sugar contents is shown on Fig. 3. In the case of sucrose, glucose, fructose and sorbitol, peaks are seen at 14:00 in the first three sampling dates. The peak is less noticeable on $20^{\text {th }}$ May, when the weather conditions were cloudy and partly rainy (meteo.si, 2017). The last sampling date was at the end of June drop. The highest amounts of all sugars were measured at 8 a.m. (8:00), then statistically significantly decreased during the day, from morning until evening. This may have been because of high temperatures on this day $\left(32.4{ }^{\circ} \mathrm{C}\right)$ (meteo.si, 2017). When temperatures exceed $30{ }^{\circ} \mathrm{C}$, temperature stress causes a slowing down photosynthetic activity (Salvucci and Crafts-Brandner, 2004). On this basis, it can be concluded that the decrease in sugar content was a consequence of temperature stress.

Comparison of daily dynamic of sugar contents with solar radiation showed delay. Solar radiation had highest values at noon (12:00), while concentrations of sugars were highest two hours later, at 14:00. This two hours delay of peaks is a consequent of metabolites transport from source (leaves) to sink (fruitlet). Klages et al. (2001) reported that carbohydrate concentrations in fruit and phloem exudates showed little diurnal variation, higher changes in the diurnal dynamic of sugars being observed in leaves. Apple leaf carbohydrates show distinct diurnal changes, with peak concentrations for sucrose at midday, followed by sorbitol and then starch in the late afternoon (Wünsche and Ferguson, 2005).

Sucrose is well known as a translocation sugar in plants. Sucrose translocated into fruit is generally generated in leaves by sucrose phosphate synthase, from leaves it is loaded into phloem and it is unloaded into the parenchyma tissue of fruit (Yamaki, 2010).

There is another form of carbon for transport along the plant in apples. The main carbon between leaves and fruitlet is sorbitol, from which other sugars are synthesized in
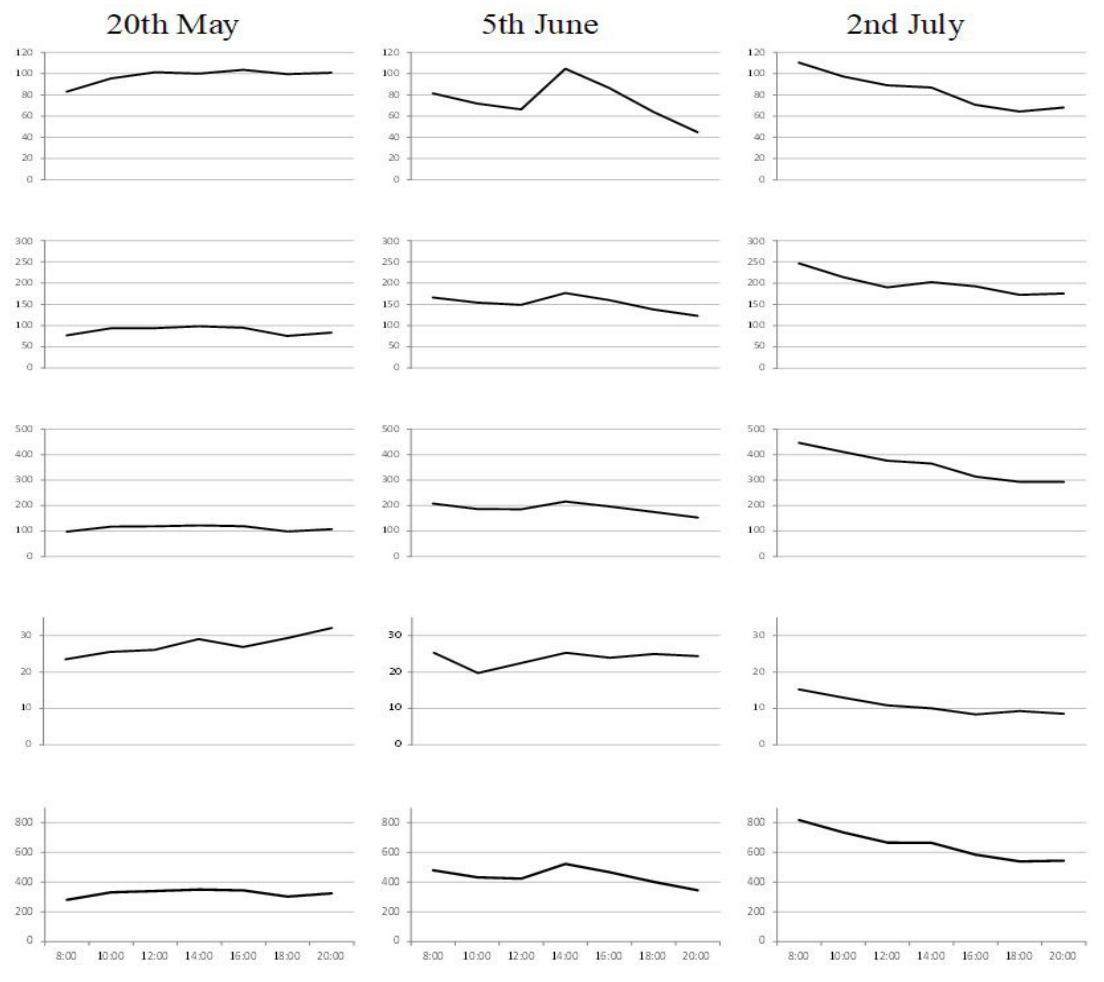

Fig. 3. Contents of individual sugars $\left(\mathrm{mg} \mathrm{g}^{-1} \mathrm{DW}\right)$, sum of sugars $\left(\mathrm{mg} \mathrm{g}^{-1} \mathrm{DW}\right)(\mathrm{n}=14)$ on each day of sampling 

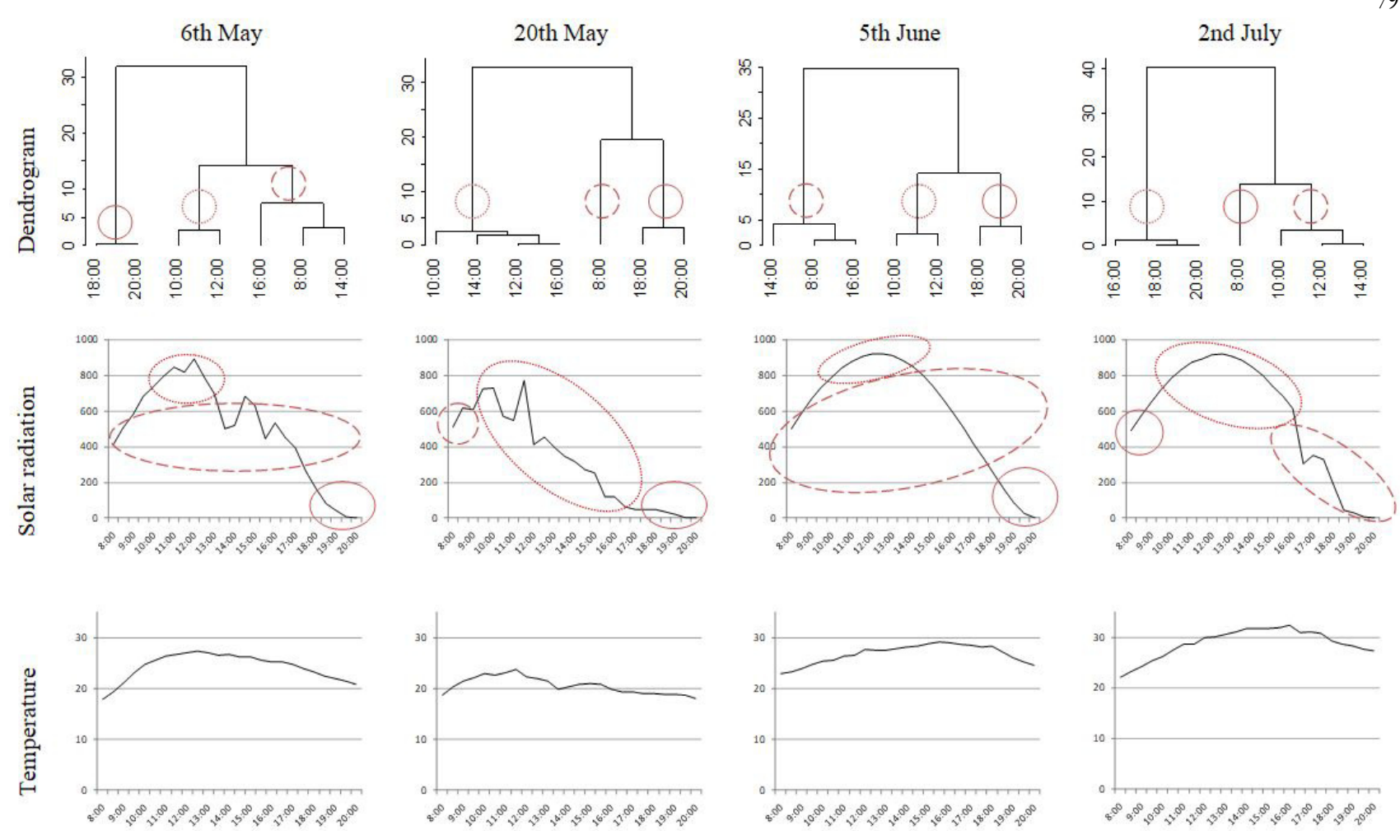

Fig. 4. Dendrograms obtained by cluster analysis of sugar content, solar radiation $\left(\mathrm{W} \mathrm{m}^{-2}\right)$ and temperatures $\left({ }^{\circ} \mathrm{C}\right)$ on each day of sampling

fruitlets (Sturm and Stampar, 1999). It can be concluded that the sorbitol content in fruitlets does not increase because of its conversion into other sugars, as was reported by Berüter (1983). Sorbitol occurs in leaves from dephosphorylation of sorbitol-6-P, which is synthesized from glucose-6-P. The sorbitol is then loaded into phloem and is translocated to the fruit. In the fruit, sorbitol is converted to fructose or glucose (Yamaki, 2010).

The grouping of sampling hours based on sucrose, glucose, fructose, sorbitol and total sugar content (dendrograms on Fig. 4) clearly relates to solar radiation. Sampling hours that are in the same group appear when solar radiation is of approximately equal value. This reflects the direct impact of daily sunlight on the content of sugars (Rosales et al., 2007).

\section{Changes in sugar content between central (king) and lateral fruitlets}

In the case of individual sugar contents, there was no interaction between time of day and the position in the cluster. The average day contents were therefore compared between central $(\mathrm{K})$ and lateral $(\mathrm{L})$ fruitlets. Total sugar content was higher in $\mathrm{K}$ fruitlets than in $\mathrm{L}$ fruitlets on all sampling dates, although the difference was not statistically significant on the last sampling date (Fig. 5). Central (K) fruitlets were richer or equal in all analyzed sugars with the exception of the first sampling date when glucose content was significantly higher in lateral fruitlets than in central fruitlets. These results are in accordance with the findings of our previous study (Jakopic et al., 2016). Higher sugar content in the central fruitlet is thus at least partly consistent with the hypothesis that central fruits profit from a better supply of sugars. Higher sugar content relates also to higher fruit dry weight (Fig. 2). This increased supply would allow the central fruit to develop at a faster rate, further increasing its sink potential (Blanke, 2009; Celton et al., 2014).

\section{Daily dynamic of total phenolic content}

The daily dynamic of total phenolic content was monitored on two sampling dates, $5^{\text {th }}$ June and $2^{\text {nd }}$ July. These two dates were chosen in order to analyze changes in total phenolic content during natural shedding and after this period. It can be seen from Fig. 6 that the contents were higher in the earlier phase of fruit development, which had also been previously reported by many authors (Akiyama $e t$ al., 2005; Mayr et al., 1995; Mikulic-Petkovsek et al., 2010). A rapid decrease in total phenolic content during June drop has been previously reported (Jakopic et al., 2016). This process indicates the high metabolic activity of apples linked to the cell enlargement stage. At the same time, the biosynthesis of specific secondary metabolites (Zheng et al., 2012) and the highest activity of selected enzymes of flavonoid biosynthesis (Treutter, 2001) has been observed.

\section{Changes in total phenolic content between central (king)} and lateral fruitlets

Although phenolic synthesis is often linked to stress defense in plants (Wang et al., 1991; Christie et al., 1994; Dixon and Paiva, 1995), we did not observe statistically significant differences in phenolic content between central and lateral fruitlets (Fig. 6). Higher phenolic contents in lateral fruitlets during fruitlets shedding and no differences between $\mathrm{K}$ and $\mathrm{L}$ fruitlets at the end of June drop may indicate higher exposure to stress but this was not confirmed in our study. 
Sucrose

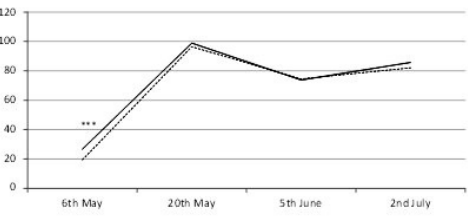

Fructose

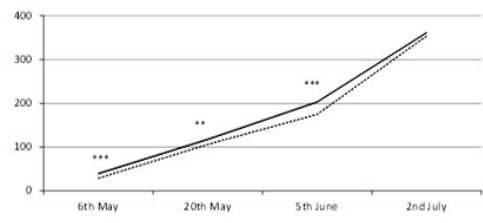

Glucose

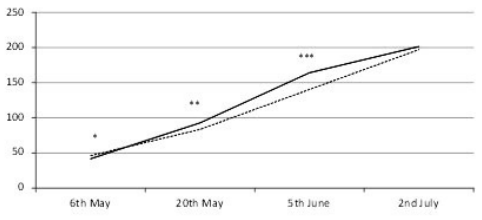

Sorbitol

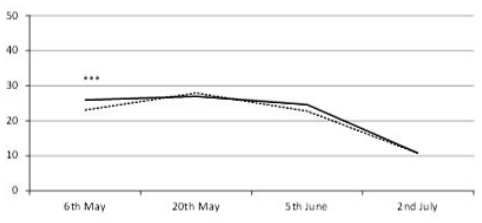

Total sugars

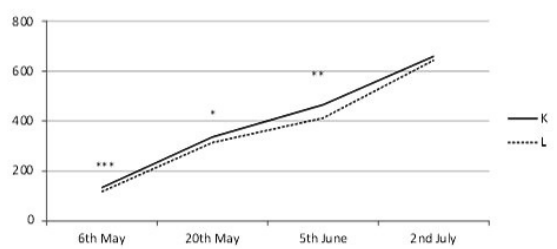

Fig. 5. The average daily content levels of individual sugars (sucrose, glucose, fructose, sorbitol) and sum of sugars $\left(\mathrm{mg} \mathrm{g}^{-1} \mathrm{DW}\right)$ in apple fruitlets. K, king or central fruitlets; L, lateral fruitlets. Asterisk indicates differences between $\mathrm{K}$ and $\mathrm{L} ;{ }^{*} p<0.05 ;{ }^{* *} p<$ 0.01 and $^{* * *} p<0.001(\mathrm{n}=35)$

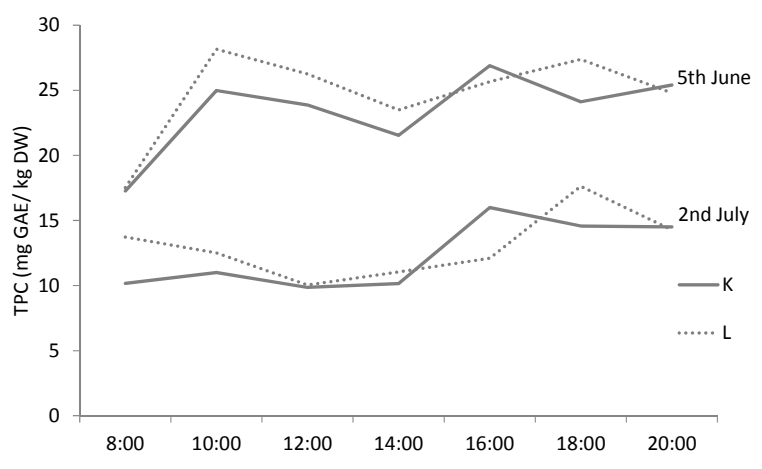

Fig. 6. Daily total phenolic content (TPC) $\left(\mathrm{mg} \mathrm{g}^{-1} \mathrm{DW}\right)$ dynamics in central $(\mathrm{K})$ and lateral $(\mathrm{L})$ fruitlets on two sampling dates

\section{Daily dynamic of total phenolic contents}

The daily dynamic of total phenolic contents indicates a lag in comparison to the peak of sugar contents. On both sampling dates, central $(\mathrm{K})$ fruitlets achieved the highest day values approximately two hours later than sugars. Additionally, lateral (L) fruitlets had a peak a further two hours later than the central fruitlet.

\section{Conclusions}

The daily dynamics of sugar content in fruitlets is strongly dependent on weather conditions. Solar radiation showed a peak around noon, while the highest day values of sugar content in apple fruitlets appeared later. An approximately two-hour delay was observed for sucrose and sorbitol, which are the main transport sugars in apples. An additional delay was noted for glucose and fructose contents, while the phenolic content in central fruitlets showed the highest daily amount at 4 p.m. and in lateral fruitlets even later, at 6 p.m.

A general influence of weather conditions was also confirmed in sugar content in apple fruitlets. On a cloudy day, the content of sugars differed slightly during the day.

\section{Acknowledgements}

This work is part of the program Horticulture P4-00130481 supported by the Slovenian Research Agency (ARRS). The authors would like to thank Nejc Rutar, International Master of Fruit Science, for his technical support at sample preparation.

\section{References}

Akiyama H, Sato Y, Watanabe T, Nagaoka MH, Yoshioka Y, Shoji T, Kanda T, Yamada K, Totsuka M, Teshima R (2005). Dietary unripe apple polyphenol inhibits the development of food allergies in murine models. FEBS Letters 579:4485-4491.

Bangerth F (2000). Abscission and thinning of young fruit and thier regulation by plant hormones and bioregulators. Plant Growth Regulation 31:43-59.

Bangerth F, Li CJ, Gruber J (2000). Mutual interaction of auxin and cytokinins in regulating correlative dominance. Plant Growth Regulation 32:205-217.

Berüter J (1983). Effect of abscisic acid on sorbitol uptake in growing apple fruits.Journal ofExperimental Botany 34:737-743.

Blanke MM (2009). Regulatory mechanisms in source sink relationships in plants-A review. Acta Horticulturae 835:13-20. 
Blanke MM, Hucklesby DP, Notton BA (1987). Distribution and physiological significance of photosynthetic phosphoenolpyruvate carboxylase in developing apple fruit. Journal of Plant Physiology 129:319-325.

Celton JM, Dheilly E, Guillou MC, Simonneau F, Juchaux M, Costes E, Laurens F, Renou JP (2014). Additional amphivasal bundles in pedicel pith exacerbate central fruit dominance and induce self-thinning of lateral fruitlets in apple. Plant Physiology 164:1930-1951.

Dal Cin V, Rizzini FM, Botton A, Tonutti P (2006). The ethylene biosynthetic and signal transduction pathways are differently affected by 1-MCP in apple and peach fruit. Postharvest Biology and Technology 42:125-133.

Dennis FG (2000). The history of fruit thinning. Plant Growth Regulation 31:1-16.

HeckeK, Herbinger K, Veberič R, Trobec M, Toplak H, Štampar F, Keppel H, Grill D (2006). Sugar-, acid-and phenol contents in apple cultivars from organic and integrated fruit cultivation. European Journal of Clinical Nutrition 60:1136-1140.

Hunter JJ, Skrivan R, Ruffner HP (1994). Diurnal and seasonal physiological changes in leaves of Vitis vinifera $\mathrm{L}$.: $\mathrm{CO}_{2}$ assimilation rates, sugar levels and sucrolytic enzyme activity. Vitis - Journal of Grapevine Research 33:189-195.

Jakopic J, Fajt N, Stampar F, Veberic R (2013). Effect of crop load on fruit quality of Fujiapple. ActaAlimentaria 42:318-327.

Jakopic J, Zupan A, Schmitzer V, Stampar F, Veberic R (2016). Sugar and phenolics level dependent on the position of apple fruitlet in the cluster. Scientia Horticulturae 201:362-369.

Jakopic J, Zupan A, Eler K, Schmitzer V, Stampar F, Veberic R (2015). It's great to be the King: Apple fruit development affected by the position in the cluster. Scientia Horticulturae 194:18-25.

Klages K, Donnison H, Wünsche J, Boldingh H (2001). Diurnal changes in non-structural carbohydrates in leaves, phloem exudate and fruit in 'Braeburn' apple. Functional Plant Biology 28:131-139.

Lakso AN, Goffinet MC (2013). Apple fruit growth. New York Fruit Quarterly 21:11-14.

Magein H (1989). Growth and abscission dynamics of Cox Orange Pippin and Golden Delicious apple fruits. Journal of Horticultural Science 64:265-273.

Mayr U, Treutter D, Santos-Buelga C, Bauer H, Feucht W (1995). Developmental changes in the phenol concentrations of 'Golden Delicious' apple fruits and leaves. Phytochemistry 38:1151-1155.
Meteosi. (2017). Retrieved 2017 April 27 from http:// meteo.arso.gov.si/met/sl/archive.

Mikulic-Petkovsek M, Slatnar A, Stampar F, Veberic R (2010). The influence of organic/integrated production on the content of phenolic compounds in apple leaves and fruits in four different varieties over a 2year period. Journal of the Science of Food and Agriculture 90:23662378.

Nebauer SG, Renau-Morata B, Guardiola JL, Molina RV (2011). Photosynthesis down-regulation precedes carbohydrate accumulation under sink limitation in Citrus. Tree physiology31:169-177.

Rosales MA, Rubio-Wilhelmi MM, Castellano R, Castilla N, Ruiz JM, Romero L (2007). Sucrolytic activities in cherry tomato fruits in relation to temperature and solar radiation. Scientia Horticulturae 113:244249.

Ruiz R, Guardiola J (1994) Carbohydrate and mineral nutrition of orange fruitlets in relation to growth and abscission. Physiologia Plantarum 90:27-36.

Ruiz R, Garca-Luis A, Monerri C, Guardiola J (2001). Carbohydrate availability in relation to fruitlet abscission in Citrus. Annals of Botany 87:805-812

Salvucci ME, Crafts-Brandner SJ (2004). Inhibition of photosynthesis by heat stress: the activation state of Rubisco as a limiting factor in photosynthesis. Physiologia Plantarum 120:179-186.

Singleton VL, Rossi JAJ (1965). Colorimetry of total phenolics with phosphomolybdic-phosphotungstic acid reagents. American Journal of Enology and Viticulture 16:144158.

Sturm K, Stampar F (1999). Seasonal variation of sugars and organic acids in apple (Malus domestica Borkh.) in different growing systems. PhytonHorn 39:91-96.

Treutter D (2001) Biosynthesis of phenolic compounds and its regulation in apple. Plant Growth Regulation 34:71-89.

Wünsche JN, Ferguson IB (2005). Crop load interactions in apple. Horticultural Reviews 31:231-290.

Yamaki S (2010). Metabolism and accumulation of sugars translocated to fruit and their regulation. Journal of the Japanese Society for Horticultural Science 79:1-15.

Zheng HZ, Kim YI, Chung SK (2012). A profile of physicochemical and antioxidant changes during fruit growth for the utilisation of unripe apples. Food Chemistry 131:106-110. 